\title{
Study on accounting methods of ship carbon emission and measures of emission reduction
}

\author{
Zhao Guodong1, a, Li Wei ${ }^{2, b}$ and Li Chunze $3, \mathrm{c}$ \\ 1'Dalian Maritime University,Dalian,Liaoning,China \\ 2 Dalian Maritime University,Dalian,Liaoning,China \\ ${ }^{3}$ Dalian Maritime University,Dalian,Liaoning,China \\ aemail : 1246929383@qq.com, bemail:724844653@qq.com, cemail:664383987@qq.com
}

\begin{abstract}
Keywords: Ship ,CO2emission, Accounting, Measures
Abstract: In recent years, with the increasing share of shipping volume in total international trade volume, the carbon emission of ships has increased year by year, and the carbon emission of ships has been paid more and more attention. This article is based on $\mathrm{CO} 2$ emissions, or tce, vessel operating efficiency index (EEOI) three aspects of ship carbon accounting methods, combination of three methods, the process of comprehensive evaluation system of carbon emissions. Taking a shipping enterprise in nanjing as an example, based on the accounting of carbon emissions from ships, reasonable measures to reduce emissions are proposed.
\end{abstract}

\section{Introduction}

with the development of the globalization of trade and shipping industry, shipping industry, the emissions also gradually into people's horizons, despite the current ship emissions accounted for about 3\% global carbon emissions, but according to IMO (international maritime organization), if there is no corresponding regulation measures, to 2050, the shipping emissions is expected to increase $50 \%$ to $250 \%$, ship the proportion of carbon emissions will rise to $12 \% \sim 18 \%$, so the urgent energy saving and emission reduction of the ship.

\section{Accounting method for carbon emission of ships}

Table $1 \mathrm{CO} 2$ emission factors of different types of fuel oil

\begin{tabular}{|l|l|l|l|}
\hline Fuel type & Carbon content & CO2 conversion factor & Equivalent tonnage coal \\
\hline Diesel oil/gasoline & 0.8744 & 3.206000 & 1.4571 \\
\hline Light fuel oil & 0.8594 & 3.151040 & 1.4286 \\
\hline Heavy fuel oil & 0.8493 & 3.114400 & 1.4286 \\
\hline Liquefied natural gas & 0.7500 & 2.750000 & 1.7572 \\
\hline
\end{tabular}

\section{CO2 emission}

$\mathrm{CO} 2$ emission of ships is the actual amount of $\mathrm{CO} 2$ emitted by ships after consumption of various types of oil during navigation. $\mathrm{CO} 2$ emission is related to fuel consumption and $\mathrm{CO} 2$ conversion coefficient of voyage classification. The specific relationship is as follows:

co2emissions $=\Sigma$ (segment classification fuel consumption * CO2 conversion coefficient)

The direct calculation of $\mathrm{CO} 2$ emissions is a simple method to calculate the carbon emissions of ships. There are fewer factors to calculate in the calculation process .

equivalent to tons of standard coal

Reduced the consumption of tce is to put the fuel converted to the corresponding content of coal, although (tce associated with the trend of $\mathrm{CO} 2$ emissions has certain are calculated based on fuel consumption, but through the converted into the content of coal energy consumption level to a more specific response of the ship. The calculation formula is as follows: Equivalent tonnage coal $=\mathrm{HFO}^{*} 1.4286+\mathrm{LFO} * 1.4286+\mathrm{DO} * 1.4571$ 
By converting the tonnage into standard coal, the imago concept of ship carbon emission can be embodied, which is more conducive to people's understanding, so that ship carbon emission can be recognized more easily.

ship efficiency operating index (EEOI)

EEOI value is vessel operating efficiency index, for the ship unit transportation amount of $\mathrm{CO} 2$ emissions, $\mathrm{CO} 2$ emissions from the consumption of fuel, and the goods/product of the number of people and transport distance and the ratio of the measure phase period of vessel operating efficiency. In this paper, the annual EEOI value was used to calculate the ship energy efficiency operating index ${ }^{[6]}$. The calculation formula is as follows:

$$
\text { Year'sEEOI }=\sum_{i} \sum_{j}(F \mathrm{Cij} * C F j) / \Sigma_{i}(m * D i)
$$

$\mathrm{J}$ is fuel type; $\mathrm{I}$ is the number of voyage; FCij is the consumption of fuel $\mathrm{j}$ in voyage $\mathrm{I}$; $\mathrm{CFj}$ is the conversion coefficient of fuel quantity and $\mathrm{CO} 2$ quantity of fuel $\mathrm{j}$. M goods are goods (tons) carried by the passenger ship or work done (TEU or passenger number) or total tons; D is the distance (nautical mile) corresponding to the cargo carried or the work done.

The EEOI accounting method is the latest version of the ship carbon emission accounting method. The smaller the EEOI value is, the higher the energy efficiency of the ship is, the more carbon emission meets the standard requirements. However, the calculation process is complex and the terminology is professional, so it is difficult for non-professionals to understand the relationship between EEOI value and ship carbon emission, which is not conducive to raising people's attention to ship carbon emission.

comprehensive accounting of ship carbon emissions based on three methods

So in the calculation of ship emissions, three kinds of carbon accounting methods should be combined, with $\mathrm{CO} 2$ emissions and reduced tce calculation method is complementary, mainly EEOI calculation method for ship research of carbon emissions. $\mathrm{CO} 2$ emissions and tonnage equivalent standard coal can accurately reflect the total carbon emissions of ships during navigation, and non-professionals can understand the carbon emissions of ships simply and clearly. EEOI carbon operating index calculation method of energy efficiency will ship with vessel operating efficiency, for ships operating properties, EEOI is used to describe the ship is more specific carbon emissions, is more persuasive.

Take a shipping enterprise in nanjing as an example to verify the comprehensive accounting method of ship carbon emissions

Based on the summary table of various fuel consumption of a shipping enterprise in nanjing in the past three years, this paper analyzes and explains the current situation of ship carbon emission by comprehensively using three accounting methods of ship carbon emission.

\section{three methods were used to calculate the carbon emission of a shipping enterprise in nanjing}

Summarize and summarize various types of fuel consumption of a shipping enterprise in nanjing.

The data are shown in the following table:

Table 2 summary of fuel consumption of a shipping enterprise in nanjing in three years

\begin{tabular}{|c|c|c|c|c|}
\hline \multicolumn{4}{|c|}{ Fuel consumption (t) } & \multirow[t]{2}{*}{ Total ship fuel (t) } \\
\hline year & Heavy fuel oil & Light fuel oil & diesel & \\
\hline 2014 & 259997.05 & 3040.37 & 17737.15 & 280774.57 \\
\hline 2015 & 236516.58 & 1296.11 & 16521.64 & 254334.33 \\
\hline 2016 & 263188.27 & 1249.24 & 19645.72 & 284083.23 \\
\hline
\end{tabular}

Two accounting methods, $\mathrm{CO} 2$ emissions and equivalent tonnage of standard coal, were used to calculate the fuel consumption for three years. The accounting results are shown in the table below: 
Table 3 summary of $\mathrm{CO} 2$ emissions and equivalent tonnage of standard coal in three years

\begin{tabular}{|l|l|l|l|l|l|l|l|l|}
\hline & \multicolumn{4}{|c|}{ CO2 emissions } & \multicolumn{4}{c|}{ Equivalent tonnage coal } \\
\hline year & HFO & LFO & diesel & In total & HFO & LFO & diesel & In total \\
\hline 2014 & 809734.81 & 9580.33 & 56865.30 & 876180.44 & 371431.79 & 4343.47 & 25844.80 & 401620.06 \\
\hline 2015 & 736607.24 & 4084.09 & 52968.38 & 793659.71 & 337887.59 & 1851.62 & 24073.68 & 401620.06 \\
\hline 2016 & 819673.55 & 3936.41 & 62984.18 & 886594.13 & 375990.76 & 1784.66 & 28625.78 & 406401.21 \\
\hline
\end{tabular}

use CO2 emissions and equivalent tons of standard coal for accounting

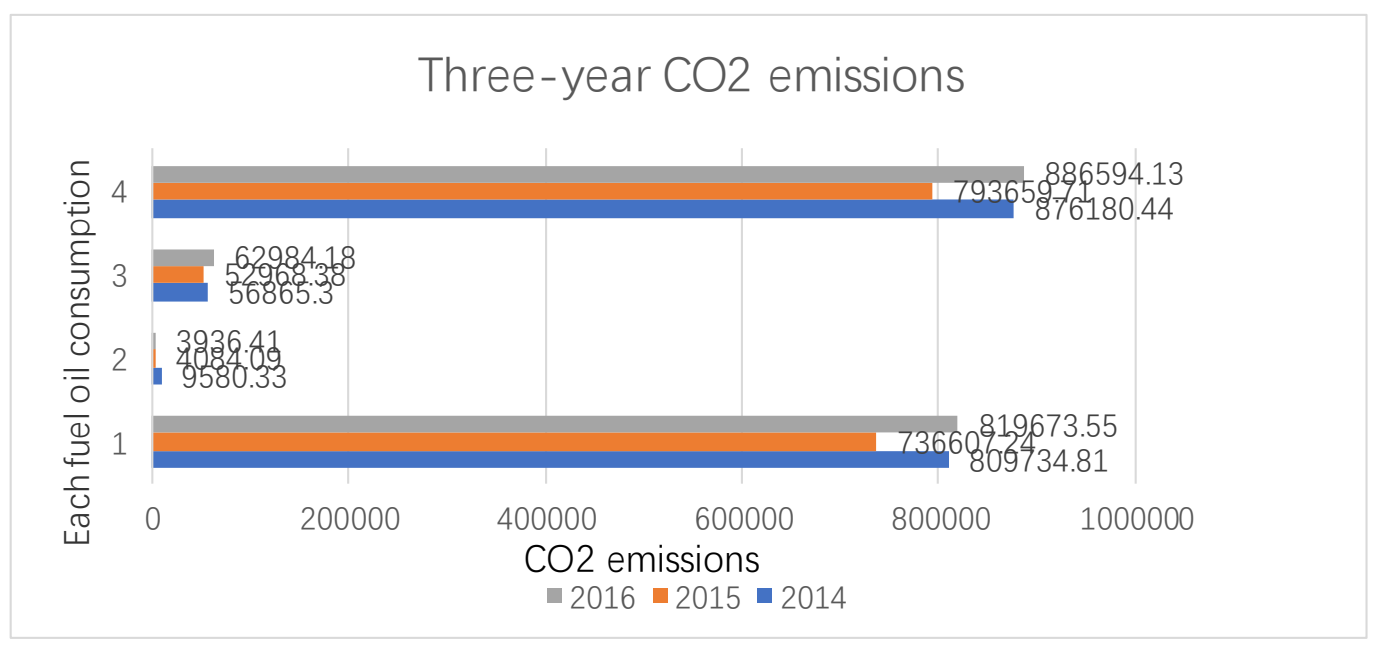

FIG.1 CO2 emissions in three years

In the table above: 1: heavy fuel oil 2: light fuel oil 3: diesel oil 4: total fuel oil

From the above table, we can see clearly in the company of the relationship between the fuel consumption and $\mathrm{CO} 2$ emissions and the status quo of carbon emissions, to ship on carbon emission reduction measures have played a guiding role.

\section{use equivalent tonnage standard coal method for accounting}

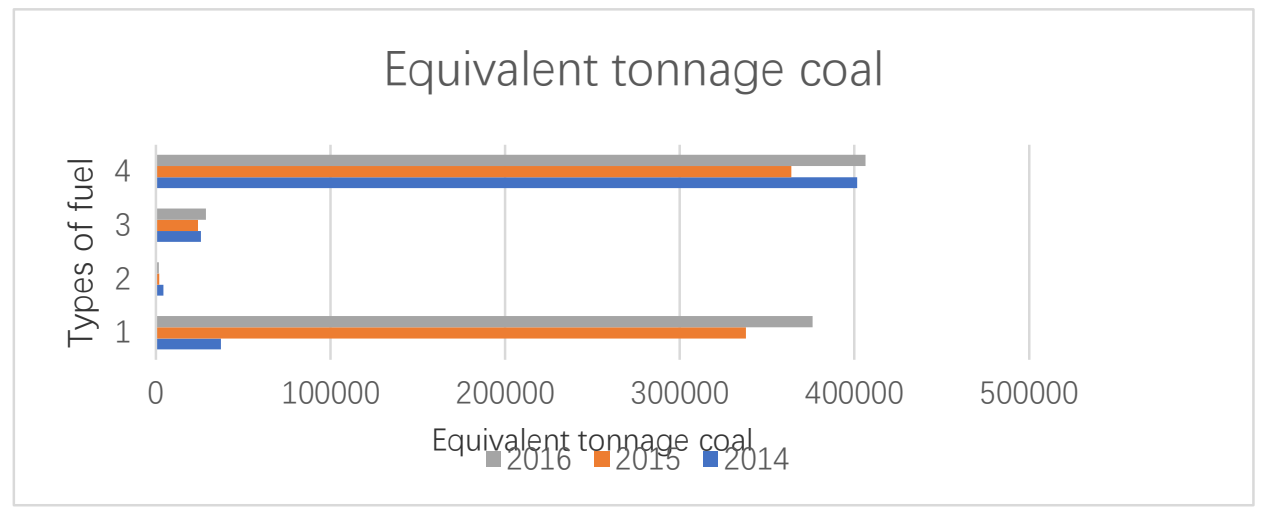

Figure 2 Equivalent tonnage coal

In the table above: 1: heavy fuel oil 2: light fuel oil 3: diesel oil 4: total fuel oil

By us know tce calculation formula and data analysis, (tce is converted to the coal consumption of $\mathrm{CO} 2$ emissions, the change tendency and the meaning and $\mathrm{CO} 2$ is similar, but the coal consumption more can reflect a ship is carbon emissions and intuitive performance for energy conservation and emissions reduction

the EEOI value of the ship energy efficiency operation index is calculated

According to the data obtained, the annual EEOI value of an oil transportation enterprise in nanjing was calculated as follows 
Table 4 annual EEOI value of a shipping enterprise in nanjing

\begin{tabular}{|l|l|}
\hline \multicolumn{2}{|c|}{ Annual EEOI value of an oil transportation enterprise in nanjing } \\
\hline year & Annual EEOI value $/(\mathrm{gCO})_{2} /$ ton $\cdot$ nautical mile $)$ \\
\hline 2014 & 8.45846502 \\
\hline 2015 & 7.45433506 \\
\hline 2016 & 7.46169176 \\
\hline
\end{tabular}

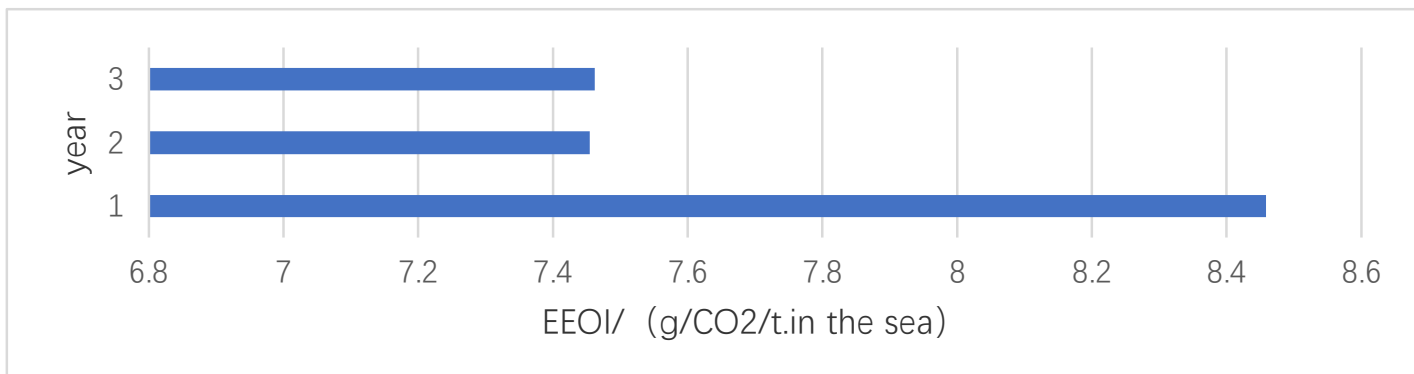

Figure 3 :The annual EEOI

As can be seen from the above table, the change trend of EEOI value decreases year by year, which can reflect that the higher the energy efficiency of this enterprise's ships, the more carbon emissions meet the emission standards. Relevant personnel can take corresponding energy-saving and emission reduction measures according to the trend of EEOI to reduce the carbon emission of ships, so as to make the carbon emission of ships meet the carbon emission standards.

comprehensive assessment of ship carbon emissions by using three accounting methods

$\mathrm{CO} 2$ emissions for the actual situation of ship emissions, $\mathrm{CO} 2$ emissions by calculation can intuitive see ships every year how much carbon emissions, and then based on the analysis of $\mathrm{CO} 2$ emissions themselves in terms of energy conservation and emissions reduction; Converted ton standard coal is the coal consumption converted into $\mathrm{CO} 2$ emissions. By calculating converted ton standard coal, the carbon emission of ships can be more reflected. The EEOI value is the ship energy efficiency index. The EEOI value can be used to judge whether the current carbon emission of ships conforms to the standard. The smaller the EEOI value is, the higher the energy efficiency of ships is. According to this data, a strict ship energy efficiency management system is established to effectively reduce ship carbon emissions.

\section{Ship emission reduction measures}

According to the above accounting information of ship carbon emission, we mainly realize the energy saving and emission reduction of ship mainly through two aspects. One is shipping companies related to the energy conservation and emissions reduction measures to reduce carbon emissions, the second is national related departments and agencies to the top design, the macroeconomic regulation and control and from aspects and so on specific policy measures to support.

\section{effective measures taken by shipping enterprises}

\section{route speed optimization}

According to different sources of voyage plan, carefully designed route, considering factors such as wind, current, wave, tidal, under the natural conditions are the same as far as possible, shorten the range, reduced endurance, optimize the speed, according to the different segments and sea roads, adopting the appropriate host speed and speed.

\section{ship operation management and maintenance}

Shipping enterprises require chief engineer and captain to strengthen the management of ship propeller to ensure that the propeller is always in high operating efficiency; The ship paint coating can make the hull surface smooth, timely clean the ship bottom attachment, reduce the ship resistance; Scientific management of ballast water, on the premise of ensuring safety, discharge ballast water as far as possible, reduce ballast water transfer, reduce ship's non-production carrying capacity, and reduce energy consumption. 


\section{carry out energy-saving activities}

Found in the actual research, key in ship energy efficiency management, completes the ship energy efficiency management propaganda education, raise awareness of the energy saving of the crew, abundant energy conservation knowledge, cultivate behavior of energy conservation and emissions reduction, is a lot of shipping companies to implement management an important means of energy efficiency of the ship.

\section{policy support provided by relevant authorities}

Shipping industry is a national macroeconomic regulation and control of the industry, has a wide coverage and involve, in August 2015 countries issued by the state council on promoting the healthy development of maritime industry several opinions, for the healthy development of shipping industry, from the macro point the way. In the actual research, it is found that enterprises hope the state to regulate from the following aspects, so as to achieve the goal of energy conservation and emission reduction.

\section{strengthen the development of shipbuilding industry}

Industry experts believe that the level of shipbuilding determines the carbon emission level of ships in future operation. High construction standards can improve the operating efficiency of ships and reduce the carbon emission of ships. China's implementation plan for accelerated structural adjustment of the shipping industry to promote transformation and upgrading (2013-2015), released in July 2013, clearly proposed that the shipbuilding industry should accelerate scientific and technological innovation.

\section{improve port facilities and supporting facilities}

As the ship itself is a transportation unit, its power system is extensive compared with that on land. If the port is equipped with relevant facilities, it can reduce the unnecessary consumption of the ship. Shore power system should be set up to close auxiliary machinery after the ship comes to port, so as to reduce the oil consumption of the ship. The establishment and improvement of the port waste oil recovery system can reduce the use of incinerators by ships and reduce fuel consumption.

\section{increase investment in $\mathbf{r} \& d$ of emission reduction equipment}

As mentioned above, the ship need not only in the process of operation optimization management, depends on the advanced equipment to reduce emissions, but these devices research often requires a lot of money, generally small and medium-sized enterprises can't support this money. The state and relevant institutions should increase investment in new technologies for emission reduction equipment and apply better energy-saving and emission reduction equipment to ships.

\section{Conclusion}

At present, low-carbon economy has become the general trend of global shipping industry development, which is also in line with the needs of The Times. In order to realize the harmonious integration and coordinated development of shipping activities and the ecological environment, it requires not only the unremitting efforts of relevant departments, but also the support of various shipping enterprises. IMO's progress in the international ocean shipping to reduce greenhouse gas emissions and its ultimate goal is still some distance, policymakers will be "profit" and "responsibility", to seek a balance between carbon road a long way to go.

\section{References:}

[1]http://www.globalcarbonproject.org/carbonbudget/index.htm

[2] IMO. Third IMO GHG Study 2014[R].London: Micropress Printers, 2015.

[3] main achievements of the 68th environmental protection conference (MEPC68) [N/0L]. China maritime safety inspection network,2015-06.03.

[4] tian guangwu. Analysis on the development of ship fuel oil [J]. Contemporary petroleum and petrochemicals, 2010, 18(8):17-20. 
[5] IMO. Guidelines for Voluntary Use of the Ship Energy Efficiency Operational Indicator (EEOI) [R]. London: Pergamon Printers, 2008.

[6] xiang xiaomin, long hua li. Interpretation of standard gb17411-2015 Marine fuel oil [J]. Petroleum business technology, 2016, 34(3):56-60.

[7] qin shi. Comparison between fuel surcharge and fuel cost of container transportation [D]. Shanghai jiaotong university, 2012.

[8] kang tianqin. Total energy system analysis based on reducing EEDI and EEOI values of ships [D]. Wuhan university of technology, 2012.

[9] wang meifei. Study on energy consumption of ships and ship efficiency design index [D]. Shanghai jiaotong university, 2014. 